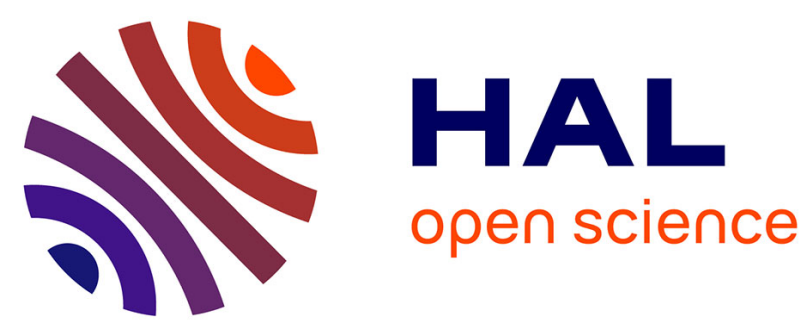

\title{
Electro-mechanical properties of thermoplastic polyurethane films and tubes modified by hybrid carbon nanostructures for pressure sensing
}

C Pérez-Aranda, Zarel Valdez Nava, F Gamboa, J Cauich-Rodríguez, F Avilés

\section{- To cite this version:}

C Pérez-Aranda, Zarel Valdez Nava, F Gamboa, J Cauich-Rodríguez, F Avilés. Electro-mechanical properties of thermoplastic polyurethane films and tubes modified by hybrid carbon nanostructures for pressure sensing. Smart Materials and Structures, 2020, 29 (11), pp.115021. 10.1088/1361665X/aba9e6 . hal-03094280

\section{HAL Id: hal-03094280 \\ https://hal.science/hal-03094280}

Submitted on 13 Jul 2021

HAL is a multi-disciplinary open access archive for the deposit and dissemination of scientific research documents, whether they are published or not. The documents may come from teaching and research institutions in France or abroad, or from public or private research centers.
L'archive ouverte pluridisciplinaire HAL, est destinée au dépôt et à la diffusion de documents scientifiques de niveau recherche, publiés ou non, émanant des établissements d'enseignement et de recherche français ou étrangers, des laboratoires publics ou privés. 


\title{
Electro-mechanical properties of thermoplastic polyurethane films and tubes modified by hybrid carbon nanostructures for pressure sensing
}

\author{
C. Pérez-Aranda a , Z. Valdez-Nava ${ }^{\mathrm{b}}$, F. Gamboa ${ }^{\mathrm{c}}$, J.V. Cauich-Rodríguez ${ }^{\mathrm{a}}$, F. Avilés ${ }^{\mathrm{a},{ }^{*}}$
}

${ }^{a}$ Centro de Investigación Científica de Yucatán, A.C., Unidad de Materiales, Calle 43 No.130 × 32 y 34, Col. Chuburná de Hidalgo, 97205, Mérida, Yucatán, Mexico.

${ }^{\mathrm{b}}$ LAPLACE, Université de Toulouse, CNRS, INPT, UPS, Toulouse, France.

${ }^{\mathrm{c}}$ Centro de Investigación y de Estudios Avanzados, Unidad Mérida, Departamento de Física Aplicada, Km. 6 Antigua carretera a Progreso Apdo. Postal 73, Cordemex, 97310, Mérida, Yucatán, Mexico.

* Corresponding author: E-mail address: faviles@ @icy.mx (F. Avilés).

Keywords: Graphene sheets; carbon nanotubes; hybrid; electrical properties; piezoresistive; pressure sensing.

\begin{abstract}
Electrical and piezoresistive properties of hybrid nanocomposite films and tubes made of a segmented aliphatic polyurethane modified with multilayer graphene sheets (MLGSs), multiwall carbon nanotubes (MWCNTs), and hybrid mixtures of both, were investigated. Hybrid nanocomposites were fabricated at a total weight concentration $\left(\Phi_{T}\right)$ of $5 \mathrm{wt} . \%$, with relative weight concentration of MLGSs with respect to MWCNTs $\left(\Phi_{R}\right)$ of $25 \%, 50 \%$ and 75\%. The electrical conductivity of these films is dominated by the MWCNT network, observing electrical MLGS-MWCNT collaborative effects only for $\Phi_{R}=25 \%$. Dielectric impedance spectroscopy indicates that the nanocomposites display capacitive effects at frequencies higher than tens of $\mathrm{Hz}$, which is explained by interfacial polarization. The burst pressure and circumferential stiffness of internally pressurized tubes fabricated from these films is slightly higher for tubes containing only MWCNTs. The strain fields in the pressurized tubes, determined by digital image correlation, showed localized strain gradients, and the piezoresistive response of the electro-conductive tubes was nonlinear. The highest pressure-sensing factor $\left(4.59 \mathrm{kPa}^{-1}\right)$ was obtained for hybrid nanocomposite tubes with $\Phi_{R}=$ $25 \%$.
\end{abstract}




\section{Introduction}

In recent decades, multifunctional and smart materials that undergo changes in their physical or physicochemical properties as a result of mechanical, thermal or electrical stimuli have attracted great interest from the scientific and industrial community. The exact definition of the term "smart material" may vary in the literature, but it can be generally defined as a material that is designed for a specific functional purpose and has one or more properties that change in a controllable fashion in response to externally applied stimuli, such as strain, stress, temperature, light, moisture, or $\mathrm{pH}$, see e.g. [1-3]. The properties of these smart materials may be further engineered to develop sensors and actuators. At present, an important scientific and technological aim is to develop flexible materials that can be used as pressure and/or deformation (strain) sensors for multifunctional applications in biomedical devices, prostheses, piping, electronic skin, and robotics, to name a few [4-11]. Particularly, in the fields of robotics and biomedicine, there is a strong demand for flexible materials in tubular form working under pneumatic mechanisms, which are capable to self-measure their strain and internal pressure during service [4-6]. In this sense, the inclusion of carbon nanostructures into flexible polymers may render electroconductive (smart) nanocomposites which are able to self-sense strain and pressure through the piezoresistive phenomenon, while delivering additional functions [3,12]. Elastomeric composites modified with carbon nanostructures such as carbon nanotubes (CNTs) and, more recently, graphenic sheets (GSs), have been used to develop flexible materials with piezoresistive properties, although the great majority of them used planar film or membrane geometry [13-20]. The inclusion of CNTs or GSs into elastomeric polymers can result in materials with high piezoresistive sensitivity, reaching gage factors (slope of strain vs. fractional change of electrical resistance, in an approximately linear zone) even of the order of a few hundreds [13-16]. Recently, it has also 
been hypothesized that a hybrid combination of CNTs and GSs could improve the electromechanical properties of such polymer nanocomposites by a synergistic or collaborative effect [21-27]. A synergistic effect would imply taking advantage of the elongated (one-dimensional) geometry of the CNTs, and of the planar (two-dimensional) geometry and high surface area of the GSs, to increase the hybrid network interaction and hence the piezoresistive sensitivity. However, despite the recent progress in this field, there are yet several unresolved issues regarding the hybrid formation and its effect on the network formation and on the effective properties of the composite. For example, it is yet not clear how CNTs and GSs interact at the nanoscale in order to form interconnected networks, which are capable of yielding synergistic or at least collaborative effects. The mere concept of "synergistic" has not been strictly defined in this field, and many studies have rushed to claim synergistic effects when they do not even represent the weighted sum of both (CNT and GS) contributions. Moreover, the large majority of the studies on carbon nanostructure-modified elastomeric nanocomposites use film or membrane geometry [13-19], and very few of them tackle the most challenging piezoresistive response of a tubular geometry [28,29]. Therefore, the aim of this work is twofold. First, it is aimed to investigate the influence of multilayer graphene sheets (MLGSs), multiwall carbon nanotubes (MWCNTs) and a hybrid combination of both on the morphology of the hybrid network formation, and its effect on the electrical properties of hybrid elastomeric nanocomposites; this is conducted using a more strict rationale based on electrical conductivity models to define possible synergistic or collaborative effects. The second aim is to extend the investigation by examining the strain and pressure self-sensing (piezoresistive) responses of hollow cylinders (tubes) under internal air pressure, manufactured with the electroconductive films obtained in the first part of the research. 


\section{Materials and methods}

\subsection{Materials}

The segmented aliphatic polyurethane (Tecoflex SG-80A, TF) was acquired from Lubrizol (Wickliffe, USA), while chloroform (J.T. Baker, purity $\geq 99.8 \%$ ) was used as solvent. MWCNTs and MLGSs were both supplied by Cheap Tubes Inc. (Vermont, USA) and they were used as received without any further treatment. MWCNTs had a purity $>95 \%$, inner diameter $\sim 4-6 \mathrm{~nm}$, outer diameter $\sim 20-40 \mathrm{~nm}$ (mean diameter of $d_{C N T}=29.1 \mathrm{~nm}$ ), length $\sim 1-6 \mu \mathrm{m}$ (mean length of $\left.L_{C N T}=2.59 \mu \mathrm{m}\right)$, and interlayer separation of $\sim 0.34 \mathrm{~nm}$, as reported elsewhere [30]. Analysis of several transmission electron microscopy images indicate that MLGSs have lateral dimensions ranging $\sim 1-5 \mu \mathrm{m}$ (mean length of $3.19 \mu \mathrm{m}$ ) and number of graphene sheets ranging 3-32. MWCNTs and MLGSs have, respectively, an atomic carbon/oxygen ratio (C/O) of 15.1 and 17.2 (obtained by X-ray photoelectron spectroscopy), D-to-G Raman spectroscopy ratio (532 nm green laser) of 0.71 and 0.25 , and average specific (Brunauer-Emmett-Teller, BET) area of $110 \mathrm{~m}^{2} / \mathrm{g}$ and $183 \mathrm{~m}^{2} / \mathrm{g}$. Further details about the physicochemical properties of both nanostructures are provided in section S1 of the supplementary information.

\subsection{Specimen fabrication}

For nanocomposite manufacturing, the carbon nanostructures (MWCNTs or MLGSs) were first dispersed in $15 \mathrm{ml}$ of chloroform using an ultrasonic probe operating at $225 \mathrm{~W}$ and 20 $\mathrm{kHz}$ during $1 \mathrm{~min}$, and subsequently with an ultrasonic bath at $110 \mathrm{~W}$ and $40 \mathrm{kHz}$ for $2 \mathrm{~h}$. Simultaneously, TF was dissolved in $15 \mathrm{ml}$ of chloroform by stirring the pellets at $125 \mathrm{rpm}$ for $2 \mathrm{~h}$. The MWCNT/MLGS/Chloroform solution was then poured into the TF/Chloroform solution and stirred at $700 \mathrm{rpm}$ for $2 \mathrm{~h}$. Then, the solution was dispersed again by using an 
ultrasonic bath at $110 \mathrm{~W}$ and $40 \mathrm{kHz}$ for $5 \mathrm{~min}$ and stirred for $15 \mathrm{~min}$ at $700 \mathrm{rpm}$. The resulting solution was cast into a rectangular glass mold, covered with a funnel to allow slow rate of solvent evaporation, and dried at room temperature $\left(\sim 25^{\circ} \mathrm{C}\right)$ for $24 \mathrm{~h}$. After drying, nanocomposites and neat TF solid films were obtained from the glass mold with dimensions of $110 \times 110 \mathrm{~mm}^{2}$ and nominal thickness of $\sim 0.12 \mathrm{~mm}$. The obtained films were further dried in a convection oven in a gradual (step-wise) fashion, to evaporate potential residual solvent. This was achieved by drying from room temperature $\left(\sim 25^{\circ} \mathrm{C}\right)$ to $60{ }^{\circ} \mathrm{C}$ in $4 \mathrm{~h}$, holding at 60 ${ }^{\circ} \mathrm{C}$ for $20 \mathrm{~h}$, heated again from $60{ }^{\circ} \mathrm{C}$ to $80{ }^{\circ} \mathrm{C}$ in $4 \mathrm{~h}$, and kept at $80{ }^{\circ} \mathrm{C}$ for another $20 \mathrm{~h}$. Additional information on specimen fabrication can be found in section $\mathrm{S} 2$ of the supplementary information.

Hollow cylinders (tubes) were manufactured by rolling chloroform-wet films onto a $6 \mathrm{~mm}$ diameter polytetrafluoroethylene (Teflon) cylindrical mandrel, and then dried in a convection oven following the procedure described above. The overhanging edges were cut to obtain tubes with $6 \mathrm{~mm}$ internal diameter, $\sim 7 \mathrm{~mm}$ external diameter $(\sim 1 \mathrm{~mm}$ wall thickness $)$ and 80 mm length.

MLGS, MWCNT and hybrid nanocomposites were prepared by mixing MLGSs and/or MWCNTs in a total weight concentration $\left(\Phi_{T}\right)$ of 5 wt.\%, defined by,

$$
\Phi_{T}=\left(\frac{m_{M W C N T}+m_{M L G S}}{m_{T}}\right)
$$

where $m_{M W C N T}$ and $m_{M L G S}$ are the mass of the MWCNTs and the MLGSs, and $m_{T}$ is the total mass of the nanocomposite (MWCNTs + MLGSs + polymer, i.e. 2 g). For hybrid composites at a fixed $\Phi_{T}=5 \mathrm{wt} . \%$, a relative MLGS weight concentration $\left(\Phi_{R}\right)$ was defined as, 


$$
\Phi_{R}=\left(\frac{m_{\mathrm{MLGS}}}{m_{M W C N T}+m_{M L G S}}\right)
$$

Table 1 summarizes the nomenclature used for the nanocomposites and their filler concentrations. For shortness, "GS" is used to refer to the hybrid nanocomposites (excepting GS100, which contains only MLGSs), and "NT" is used for nanocomposites with only MWCNTs. The number that follow the labels of the hybrid nanocomposites (GS\#) indicates the relative concentration (in weight percentage) of MLGSs in the nanocomposite. In order to provide more information to assess the MLGS-MWCNT interactions in the hybrid composites, additional nanocomposites with only MWCNTs but less $\Phi_{T}$ were fabricated (NT75, NT50, and NT25). These nanocomposites have a total weight concentration of $\Phi_{T}=$ $1.25 \%$ (NT25), $2.5 \%$ (NT50), and 3.75\% (NT75) and served for direct comparison of the electrical conductivity with hybrid nanocomposites with $\Phi_{R}=75 \%$ (GS75), 50\% (GS50), and 25\% (GS25), respectively. Additionally, the weight concentration of MWCNTs in the composite $\left(\Phi_{C N T}\right)$ is a parameter that is of use for the electrical conductivity analysis, and is defined as,

$$
\Phi_{C N T}=\left(\frac{m_{M W C N T}}{m_{T}}\right)
$$

Notice in Table 1 that, for example, NT75 has the same total mass of MWCNTs $\left(\Phi_{C N T}=\right.$ 3.75 wt.\%) than GS25, but NT75 does not contain MLGSs (only MWCNTs). 
Table 1. Nanocomposites nomenclature, masses employed for $m_{T}=2 \mathrm{~g}$, and concentrations of MLGSs and MWCNTs.

\begin{tabular}{|c|c|c|c|c|c|c|}
\hline Composite & $\begin{array}{c}m_{M W C N T} \\
(\mathbf{m g})\end{array}$ & $\begin{array}{c}m_{M L G S} \\
(\mathbf{m g})\end{array}$ & $\begin{array}{c}\Phi_{C N T} \\
(\text { wt. } \%)\end{array}$ & $\begin{array}{c}\Phi_{T} \\
(\text { wt. } \%)\end{array}$ & $\begin{array}{c}\Phi_{R} \\
(\text { wt. \%) }\end{array}$ & Description \\
\hline $\mathrm{TF}$ & 0 & 0 & 0 & 0 & - & $\begin{array}{l}\text { Neat polyurethane (Tecoflex } \\
\text { SG-80A). }\end{array}$ \\
\hline GS100 & 0 & 100 & 0 & 5 & 100 & Only MLGSs. \\
\hline GS75 & 25 & 75 & 1.25 & 5 & 75 & $\begin{array}{l}\text { Hybrid concentration with } 75 \% \\
\text { MLGSs and } 25 \% \text { MWCNTs. }\end{array}$ \\
\hline GS50 & 50 & 50 & 2.5 & 5 & 50 & $\begin{array}{l}\text { Hybrid concentration with } 50 \% \\
\text { MLGSs and 50\% MWCNTs. }\end{array}$ \\
\hline GS25 & 75 & 25 & 3.75 & 5 & 25 & $\begin{array}{l}\text { Hybrid concentration with } 25 \% \\
\text { MLGSs and } 75 \% \text { MWCNTs. }\end{array}$ \\
\hline NT100 & 100 & 0 & 5 & 5 & 0 & Only MWCNTs. \\
\hline NT75 & 75 & 0 & 3.75 & 3.75 & 0 & $\begin{array}{l}\text { Only MWCNTs in the same } \\
\text { concentration than GS } 25 \text {. }\end{array}$ \\
\hline NT50 & 50 & 0 & 2.5 & 2.5 & 0 & $\begin{array}{l}\text { Only MWCNTs in the same } \\
\text { concentration than GS50. }\end{array}$ \\
\hline NT25 & 25 & 0 & 1.25 & 1.25 & 0 & $\begin{array}{l}\text { Only MWCNTs in the same } \\
\text { concentration than GS75. }\end{array}$ \\
\hline
\end{tabular}

\subsection{Optical and scanning electron microscopy}

Optical microscopy of the nanocomposite films was carried out with a Leica Microsystems

DM LM optical microscope (Wetzlar, Germany) using transmitted light. The samples were obtained from a drop of the same suspension/solution used for preparing the nanocomposites, pressing the drop between two glass slides and allowing drying.

Scanning electron microscopy (SEM) was carried using a JEOL JSM-6360-LV microscope (Tokyo, Japan). The surface of the nanocomposites was analyzed using square samples with $\sim 3 \mathrm{~mm}$ side-length cut from the nanocomposite films. The SEM images were obtained 
without sample metallization, using an acceleration voltage of $20 \mathrm{kV}$ and working distance between 10 and $12 \mathrm{~mm}$.

\subsection{Electrical characterization of nanocomposite films}

The electrical conductivity in direct current (DC) of the nanocomposites was measured by using a high resistivity electrometer (Keithley 6517B, Cleveland, USA), using the 2-point probe (2-wire) method. Rectangular film specimens of $20 \mathrm{~mm}$ length, $10 \mathrm{~mm}$ width and $\sim 0.12$ mm thickness were used. Electrodes were defined using "Bare Conductive" (London, England) conductive paint, placed at the ends of the specimen, with a separation of $10 \mathrm{~mm}$. The electrical resistance of all specimens was in the $\mathrm{M} \Omega$ range, and differences in electrical resistance between the 2-point and 4-point probe methods were less than $2.4 \%$ (see section S3.1 of the supplementary information). Thus, the use of the 4-point probe method was deemed unnecessary.

A special guard (model 8009 from Keithley Instruments) was used to measure the electrical resistivity of the most insulating materials, i.e. pure polymer (TF) and nanocomposites NT75, GS75 and GS100. In this case, circular specimens were cut from the films with $90 \mathrm{~mm}$ diameter and $\sim 0.12 \mathrm{~mm}$ thickness, in order to fit the circular electrodes of the commercial guard. Ten replicates per group were measured.

The Voigt and Reuss (series and parallel) electrical models [31] were originally developed to describe properties of fiber-reinforced oriented composites in their longitudinal and transverse directions. Although they are not directly applicable to nanoparticle-filled composites, they can still provide a first approach to define upper and lower limits of the expected properties. Taking into account this, two semi-empirical models are proposed here as a calibrated frame of reference for the conductivity of the nanocomposites, adapting the 
original Voigt and Reuss models to represent the weighted average of the constituent nanocomposites (instead of the weighted average of the matrix and filler), i.e.,

$$
\begin{gathered}
\sigma_{e}=\sigma_{e_{N T 100}}\left(1-\phi_{V_{R}}\right)+\sigma_{e_{G S 100}} \phi_{V_{R}} \\
\sigma_{e}=\left(\frac{\left(1-\phi_{V_{R}}\right)}{\sigma_{e_{N T 100}}}+\frac{\phi_{V_{R}}}{\sigma_{e_{G S 100}}}\right)^{-1}
\end{gathered}
$$

where $\sigma_{e_{N T 100}}$ and $\sigma_{e_{G S 100}}$ are the measured electrical conductivities of the nanocomposites NT100 and GS100, respectively. $\phi_{V_{R}}$ is the relative volume concentration (vol.\%) of MLGSs, which is expressed by,

$$
\phi_{V_{R}}=\frac{V_{M L G S}}{V_{M W C N T}+V_{M L G S}}
$$

Volume fractions were obtained by means of the corresponding densities, i.e. $V_{x}=m_{x} / \rho_{x}$, where " $x$ " can be MWCNT, MLGS or TF; $\rho_{M W C N T}, \rho_{M L G S}$ and $\rho_{T F}$ are the density of the MWCNTs $\left(2.1 \times 10^{6} \mathrm{~g} / \mathrm{m}^{3}[24]\right)$, MLGSs $\left(2.2 \times 10^{6} \mathrm{~g} / \mathrm{m}^{3}[24]\right)$ and TF $\left(1.04 \times 10^{6} \mathrm{~g} / \mathrm{m}^{3}\right)$.

Notice that these modified series, Eq. (4a), and parallel, Eq. (4b), models are calibrated in such a way that they employ the measured data for nanocomposites with only one filler, i.e. $0 \%$ (NT100) and 100\% of MLGSs (GS100), to predict the electrical conductivity of hybrid nanocomposites at an intermediate MLGS concentration.

Electrical properties in alternating current (AC) were obtained by analyzing the phase shift of the voltage and current signals of the specimens in a frequency range of $10^{-1}$ to $10^{7} \mathrm{~Hz}$ at an applied voltage of $1 \mathrm{~V}_{\text {rms. }}$. For this, an Alpha-A broadband dielectric spectrometer from Novocontrol Technologies (Montabaur, Germany) was used. The nanocomposite films ( $\sim 0.12 \mathrm{~mm}$ thickness) were cut into circular specimens of $35 \mathrm{~mm}$ diameter and sputtered with high purity gold (thickness $\sim 50 \mathrm{~nm}$ ) on both sides, defining $25 \mathrm{~mm}$ diameter electrodes. All samples reported herein were tested at room temperature $\left(\sim 25^{\circ} \mathrm{C}\right)$. Further information of 
the experimental setup used for electrical measurements (both, in DC and AC) is provided in section S3.1 of the supplementary information.

\subsection{Mechanical and piezoresistive characterization of tubes}

Hollow cylinders (tubes) of $80 \mathrm{~mm}$ long, $6 \mathrm{~mm}$ inner diameter and $\sim 1 \mathrm{~mm}$ wall thickness (see Fig. 1a) were manufactured from the nanocomposite films NT100, GS25, GS50, GS75 and GS100, as well as from the neat polymer (TF). GS50, GS75 and GS100 nanocomposites were only tested mechanically (burst strength), since their electrical conductivity in tube geometry was not enough to characterize their piezoresistivity. The burst strength test (internally pressurized cylinder) [32] using air pressure, was conducted with an equipment specifically designed and manufactured for this type of test [33], as depicted in Fig. S7 of section S3.2 of the supplementary information. This equipment pumps filtered air into the tubular specimen and gradually increases the internal pressure (at $1 \mathrm{psi} / \mathrm{s}, \sim 6.9 \mathrm{kPa} / \mathrm{s}$, for all tests herein) while continuously measures its diameter using a laser curtain micrometer (optoCONTROL 1200-30 from Micro-Epsilon, Ortenburg, Germany). Circumferential strain $\left(\varepsilon_{\theta}\right)$ was calculated as the instantaneous change in diameter divided by the initial diameter, and tube compliance was obtained from the slope of the pressure $(P)$ vs. $\varepsilon_{\theta}$ curve at strains $\varepsilon_{\theta} \leq 5 \%$.

In order to conduct piezoresistive tests of NT100 and GS25 nanocomposite tubes, 40-gauge copper wires were cemented (using "Bare Conductive" paint) on two opposite sides of the circumference of the tubes (see Fig. 1a), forming $5 \mathrm{~mm}$ side-length square electrodes. The electrical resistance was measured using the 6517B Keithley electrometer described earlier. Since it was experimentally confirmed that the thin electrodes did not affect the mechanical response, the mechanical and piezoresistive responses were obtained simultaneously (from the same specimen/test). Five tubular specimens were tested for each type of nanocomposite. 
To quantify the piezoresistive sensitivity of the tubes, a gage factor $\left(G F^{T}\right)$ was defined by,

$$
G F^{T}=\frac{\Delta R / R_{0}}{\varepsilon_{\theta}}
$$

where $R$ is the instantaneous electrical resistance, $R_{0}$ is the initial (unloaded) electrical resistance, and $\Delta R / R_{0}$ is the fractional change in electrical resistance. Given the nonlinear piezoresistive response of the specimens, gage factors were calculated in two regions of the $\Delta R / R_{0}$ vs. $\varepsilon_{\theta}$ curves (I and II). $G F^{T}{ }_{I}$ was obtained from $0 \leq \varepsilon_{\theta} \leq$ to $5 \%$ (region I), while $G F^{T}{ }_{I I}$ (region II) was obtained from $15 \leq \varepsilon_{\theta} \leq 20 \%$. Also, the pressure sensitivity factors $(P F)$ of tubes were obtained as a function of the applied (internal) pressure $(P)$ as,

$$
P F=\frac{\Delta R / R_{0}}{P}
$$

Similar to gage factors, the pressure sensitivity factors were measured at two regions of the $\Delta R / R_{0}$ vs. $P$ curves, viz. $0 \leq P F_{I} \leq 35(\mathrm{kPa})$ and $150 \leq P F_{I I} \leq 200(\mathrm{kPa})$.

An ARAMIS 5M digital image correlation (DIC) equipment from GOM (Brunswick, Germany) was used to measure the strain fields of the tubular specimen upon pressure. For this purpose, an speckle pattern was painted on the surface of the tube with an area of $50 \times 6$ $\mathrm{mm}^{2}$ (see Fig. 1c). Images were captured using two $2448 \times 2050$ pixels ( $5 \mathrm{Mpx}$ ) cameras, with $35 \mathrm{~mm}$ Schneider lenses, using a $35 \times 29 \mathrm{~mm}$ field of view, and a camera distance of $21.5 \mathrm{~cm}$, as shown in Fig. 1b. The full experimental setup can be seen in Fig. S7 of section S3.2 of the supplementary information. Figure 1c shows the speckle pattern and mask (measurement zone) used to measure the DIC strain fields. The DIC mask is placed between the electrodes (see Fig. 1a) and has an approximate length of $50 \mathrm{~mm}$ and an arc-width of $6 \mathrm{~mm}$. In this area, the strain fields along the $x, y, z$ axes $\left(\varepsilon_{x}, \varepsilon_{y}, \varepsilon_{z}\right)$ were measured, according to the axes depicted in Fig. 1c. 


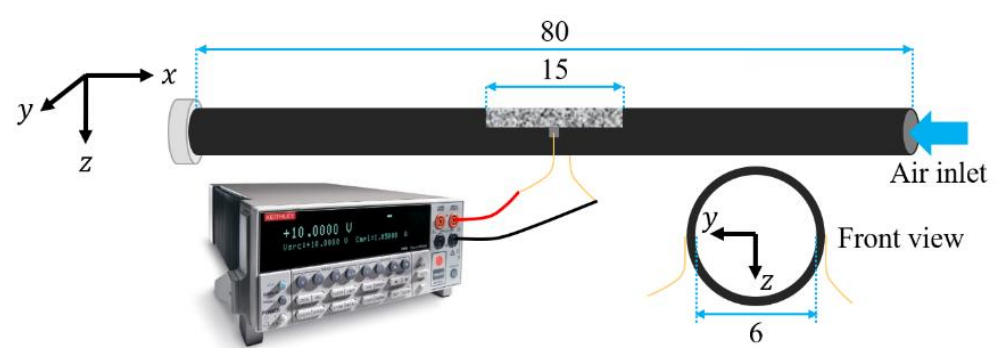

a)

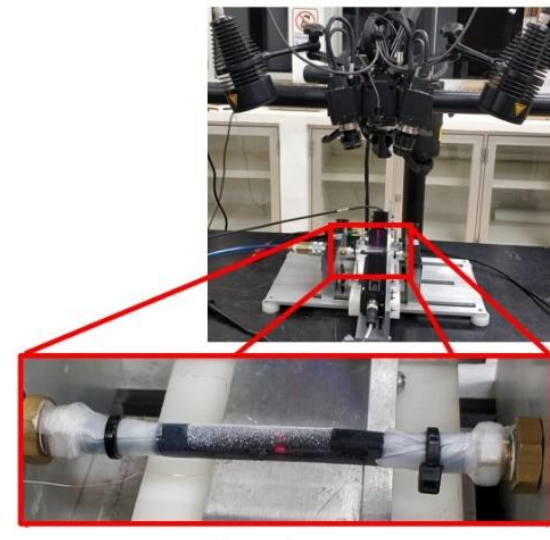

Specimen

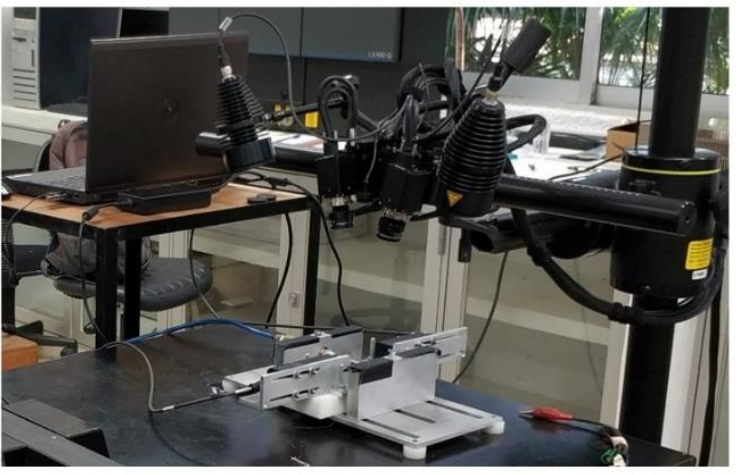

DIC system

b)

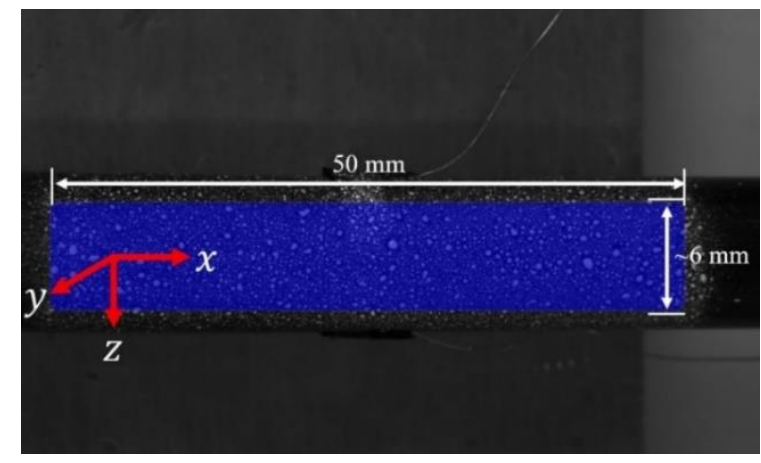

c)

Fig. 1. Burst strength test of the nanocomposite tubes. a) Schematic of the tube and meter, b) photograph of the experimental setup, c) DIC measurement mask on a tube.

\section{Results}

\subsection{Visualization of the interconnected networks}

Figure 2 shows optical microscopy images of the nanocomposite films with a magnification of 10x. It is seen that carbon nanostructures form interconnected networks within the polymer matrix, comprising well-distributed groups of nanostructures but also some heterogeneous islands of grouped nanostructures, especially for the hybrid nanocomposites (GS25, GS50, 
and GS75). The agglomerates found in the nanocomposites with a single type of nanostructure (NT100 or GS100) are smaller than those found in the hybrid nanocomposites (GS25, GS50 and GS75), achieving better dispersion and distribution for composites with only MWCNTs (NT100). Agglomerates in CNT and graphenic nanocomposites are typically attributed to van der Waals and Coulombic attractions [34]. The elongated geometry and high aspect ratio of MWCNTs promote agglomeration, as has been previously pointed out [34]. On the other hand, given the geometry, two-dimensional topology and flexibility of MLGS, they are prone to become folded or crimpled when dispersed into a polymer matrix $[35,36]$. It is worth noticing that the network morphology of the hybrid nanocomposites is very different from that of GS100 and NT100. This fact suggests that the morphology and dimensionality of the nanostructure plays a paramount role in their physico-chemical interactions and consequent network formation, especially for non-functionalized nanostructures such as those used herein. Furthermore, the surface area of MWCNTs and MLGSs (see section S1.1 of the supplementary information), as well as their compatibility with the solvent (chloroform), are determining factors in their state of dispersion $[37,38]$. Compared to MWCNTs, MLGSs have a larger surface area, which implies a higher tendency to agglomerate. 


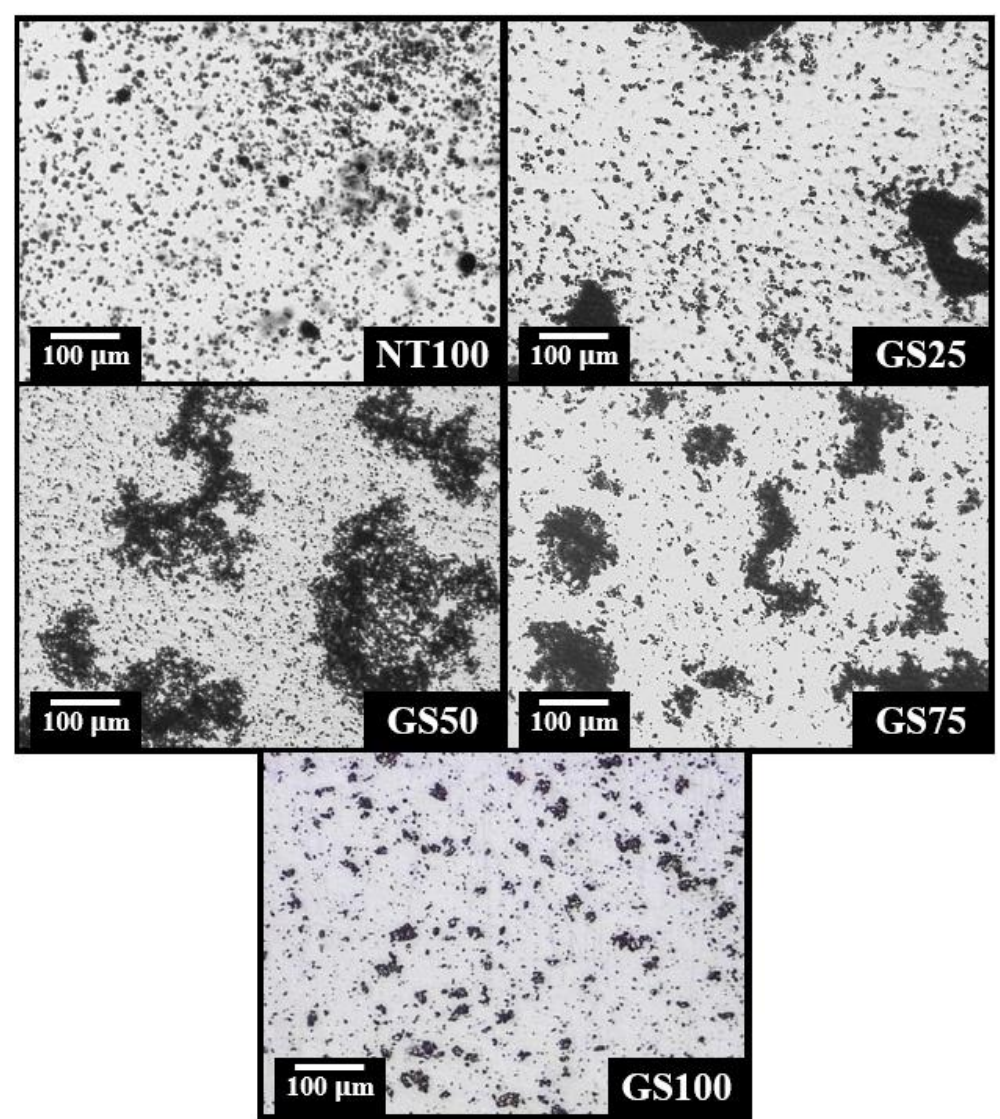

Fig. 2. Optical microscopy images of the hybrid nanocomposites showing the fillers (dark entities) dispersed within the polymer matrix.

Further confirmation of the dispersion state can be obtained from the SEM images of Fig. 3, although in a significantly smaller scale. In this scale, the MWCNTs still show signs of agglomeration, and better dispersion than the MLGSs. For the GS25 hybrid, MWCNTs and MLGSs are intercalated within the polymer matrix. Similar features are observed in the other two hybrid nanocomposites (GS50 and GS75), but the presence of stacked MLGSs is more evident. The greater tendency of the MLGSs to stack and agglomerate as compared to the MWCNTs, can be attributed to their higher specific surface area $\left(\sim 183 \mathrm{~m}^{2} / \mathrm{g}\right.$, see Table S1). It is also observed that some MLGSs present an irregular geometry, with dimensions significantly smaller than the few microns expected. This can be attributed to the 
manufacturing process of the nanocomposites, where the MLGSs are prone to fold and crumple during nanocomposite processing.
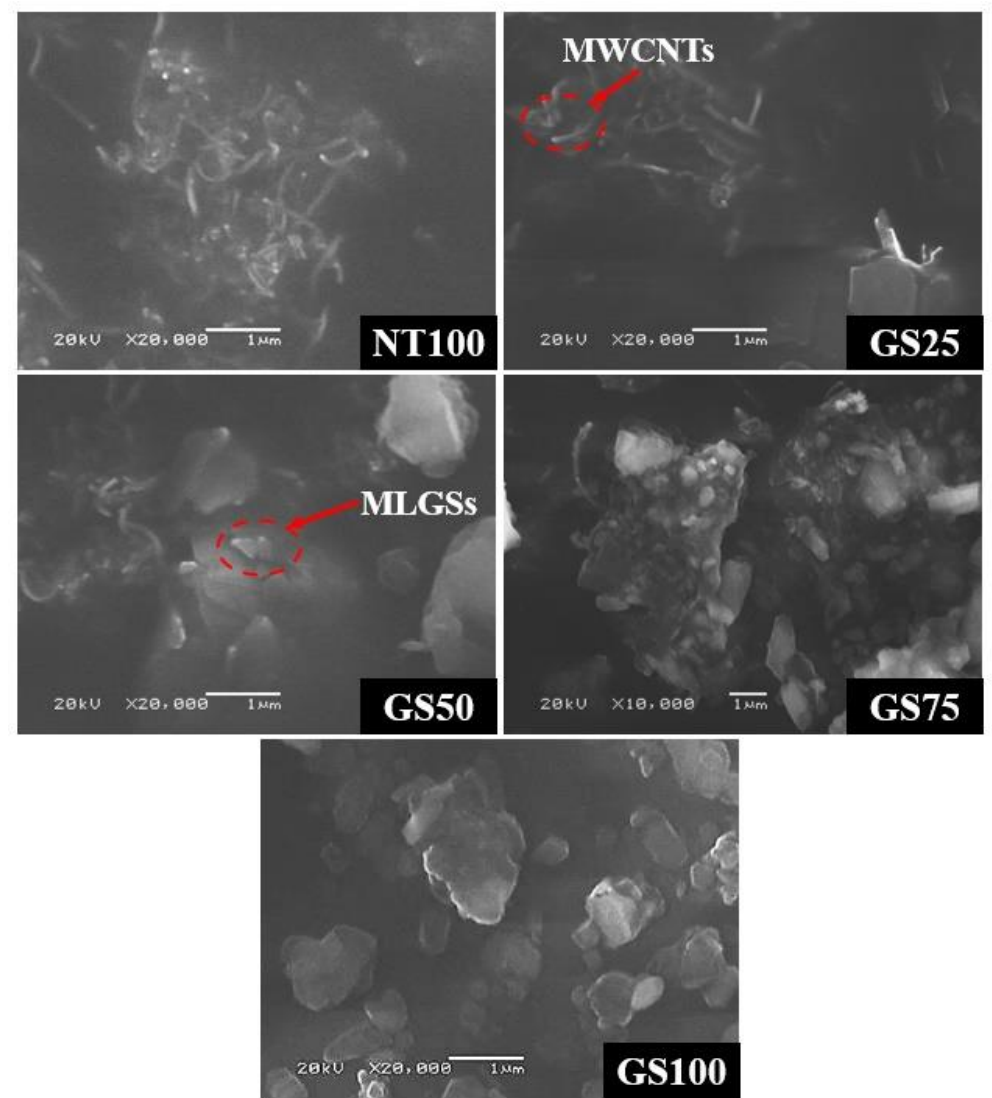

Fig. 3. SEM images of the nanocomposites showing MWCNTs and MLGSs dispersed in the polymer matrix.

\subsection{Electrical conductivity in direct current}

Figure 4 shows the electrical (DC) conductivity $\left(\sigma_{e}\right)$ of the investigated films as a function of $\Phi_{R}$ (bottom horizontal axis) and $\Phi_{C N T}$ (top horizontal axis). The continuous plots produced by the semi-empirical models stated in Eqs. (4) are included in this graph. It is clear that the conductivity of TF $\left(\sigma_{e_{T F}}=3.16 \times 10^{-13} \mathrm{~S} / \mathrm{m}\right)$ increases several orders of magnitude with the inclusion of carbon nanostructures (MWCNTs or MLGSs). The electrical conductivity varies according to the relative concentration of MLGSs with respect to that of MWCNTs $\left(\Phi_{R}\right)$, being higher for nanocomposites with only MWCNTs $\left(\sigma_{e_{N T 100}}=1.33 \times 10^{-3} \mathrm{~S} / \mathrm{m}\right)$, and 
decreasing as the MWCNTs are replaced by MLGSs, until the lowest value is reached for GS100 $\left(\sigma_{e_{G S 100}}=1.01 \times 10^{-9} \mathrm{~S} / \mathrm{m}\right)$. This decrease in electrical conductivity as the relative concentration of MLGSs increases is not linear, showing a sigmoidal behavior (for $\log \left[\sigma_{e}\right]$ ), as pointed out in Fig. S8 of section S4 in the supplementary information. The higher electrical conductivity of nanocomposites with MWCNTs with respect to that of nanocomposites with MLGSs can be explained by the geometry, morphology (long tubes against disks), and dimensions of both nanostructures, and is supported by the theory of excluded volume [39], as further explained in section S5 of the supplementary information. In addition, the tunneling effect between nanostructures plays an important role in the electrical conductivity and piezoresistivity of this type of nanocomposites [40,41]. Electrons between conductive fillers can quantumly tunnel through a thin layer of insulating polymer, which has been estimated to be less than $\sim 5 \mathrm{~nm}[40,41]$. The effective electrical conductivity of the nanocomposites strongly depends on the agglomerate size, and how these agglomerations are distributed within the polymer $[42,43]$. The elongated geometry of the MWCNTs and better agglomerate distribution observed in Fig. 2 and 3, may be a contributed factor for their better electronic transport. The semi-empirical models of Eq. (4) enclose the measured data in Fig. 4, given that they are calibrated with the measured conductivity of NT100 and GS100 nanocomposites. The model of Eq. (4a) (series model) for hybrids represents a simple weighted summation of the contribution of each nanocomposite comprising a single nanostructure (NT100 and GS100); as such, it is proposed here to represent a boundary that can be used as a reference frame to distinguish the electrical interaction between the hybrid nanostructures within the nanocomposite (either synergistic or collaborative), as depicted in Fig. 4. This is, if the electrical conductivity of the nanocomposite is above the weighted sum 
of the electrical conductivity of the nanocomposites with a single type of filler, Eq. (4a), then a synergistic effect is identified. If the conductivity is not higher than that predicted by Eq. (4a), but still higher than that of the single-filler MWCNT nanocomposites at identical $\Phi_{C N T}$ (NT75, NT50, and NT25, for $\Phi_{R}=25 \%, 50 \%$ and 75\%, respectively), then a collaborative effect is expected. As seen from Fig. 4, in the case of the nanocomposites examined herein, for $\Phi_{R}=25 \%$ (GS25 nanocomposites in Table 1) there are collaborative electrical effects between the MWCNTs and the MLGSs. However, for $\Phi_{R}=50 \%$ and 75\%, the conductivity is predominantly governed by that of the MWCNT network, and the MLGS have further no significant effect on the conductivity of the hybrid nanocomposite. This is undoubtedly related to the morphology of the network of carbon nanostructures formed within the nanocomposite (Fig. 2 and 3), as well as to the dimensionality, size, agglomeration state, and physicochemical properties of the nanostructures, as reported in section S1 of the supplementary information. As seen in Table S1 of the supplementary information, the nanostructures used herein contain low functionalities (less for MLGSs), less surface area and higher aspect ratio for MWCNTs, yielding better dispersion for MWCNT composites. However, it has been pointed out that well distributed, connected agglomerates of moderate size may enhance the electrical conductivity of polymer nanocomposites [42]. 


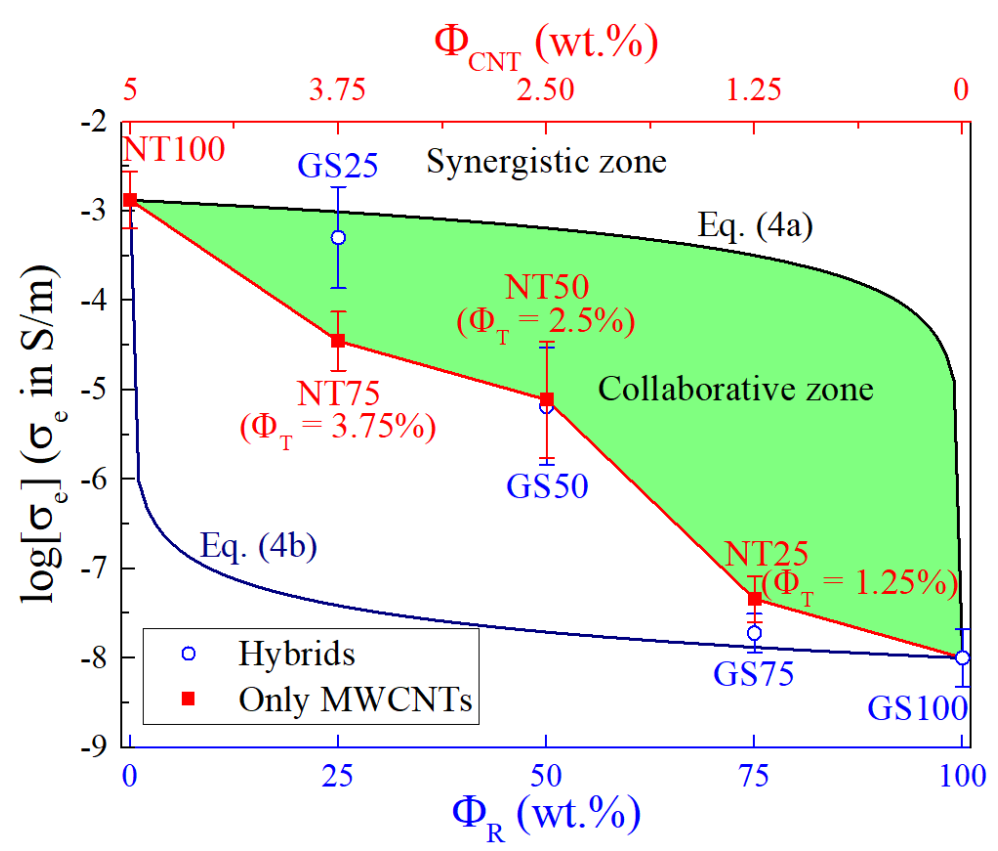

Fig. 4. Measured electrical conductivity of the films (data points) and models (Eq. (4), continuous lines), defining the synergistic and collaborative zones.

\subsection{Electrical properties in alternating current}

Figure 5 shows the real $\left(\sigma_{e}{ }^{\prime}\right.$, Fig. 5a) and imaginary $\left(\sigma_{e}{ }^{\prime \prime}\right.$, Fig. $\left.5 b\right)$ components of the AC electrical conductivity of the nanocomposites as a function of AC frequency $(f)$. As seen from Fig. 5a, the hybrid nanocomposites have a higher conductivity $\left(\sigma_{e}{ }^{\prime}\right)$ as the relative concentration of MWCNTs with respect to that of MLGS increases, with the maximum conductivity for nanocomposites with only MWCNTs (NT100) and minimum for GS100. This is consistent with the results of the DC electrical conductivity shown in Fig. 4. For all nanocomposites, $\sigma_{e}{ }^{\prime}$ remains constant (resistive-like behavior) at low frequencies and increases linearly at higher frequencies (capacitive-like behavior), leveling off as $f$ approaches $\sim 10^{7} \mathrm{~Hz}$. The critical frequency $\left(f_{c}\right)$ at which the trend of $\sigma_{e}{ }^{\prime}$ changes (from resistive to capacitive), varies depending on the MLGS/MWCNT ratio, $\Phi_{R}$. For the imaginary component $\left(\sigma_{e}{ }^{\prime \prime}\right.$, Fig. 5b), a linear increase of $\sigma_{e}{ }^{\prime \prime}$ as a function of $f$ is seen for all materials investigated. NT100, GS25 and GS50 have a $\sigma_{e}{ }^{\prime \prime}$ of approximately one order of 
magnitude higher than that of GS75 and GS100, with particularly important differences for frequencies below $10^{4} \mathrm{~Hz}$. The increase of $\sigma_{e}{ }^{\prime \prime}$ with increased $f$ indicates an important capacitive contribution in the impedance of the nanocomposite, see e.g. [43,44]. Since $\sigma_{e}{ }^{\prime \prime}$ correlates with the difficulty for charge carriers to respond to rapid changes in the applied electric field, this can be related to an interfacial polarization which occurs in the nanocomposites when an AC electric field is applied [45,46]. Figure 5c shows the critical frequency $\left(f_{c}\right)$ as a function of $\Phi_{R}$. Herein, $f_{c}$ was calculated as the intersection of two straight lines corresponding to the slopes of each linear zone, as depicted in the inset of Fig. 5c. From Fig. 5c, it is observed that the highest critical frequency $\left(f_{c}=166 \mathrm{kHz}\right)$ corresponds to NT100, while the lowest ones $(6.5-8.7 \mathrm{~Hz})$ correspond to G100 and G75 nanocomposites. GS50 presents an average $f_{c}=789 \mathrm{~Hz}$ with relatively large dispersion in the measured values among replicates (standard deviation), marking a transition between the dominance of MWCNTs and MLGSs. The higher data scattering for this nanocomposite is believed to be due to the random filler dispersion in the nanocomposites, their 50:50 hybrid constitution, and the increased structure-property (dispersion-conductivity sensitivity) relationship of this 50:50 hybrid network, since it is in the vicinity of electrical percolation.

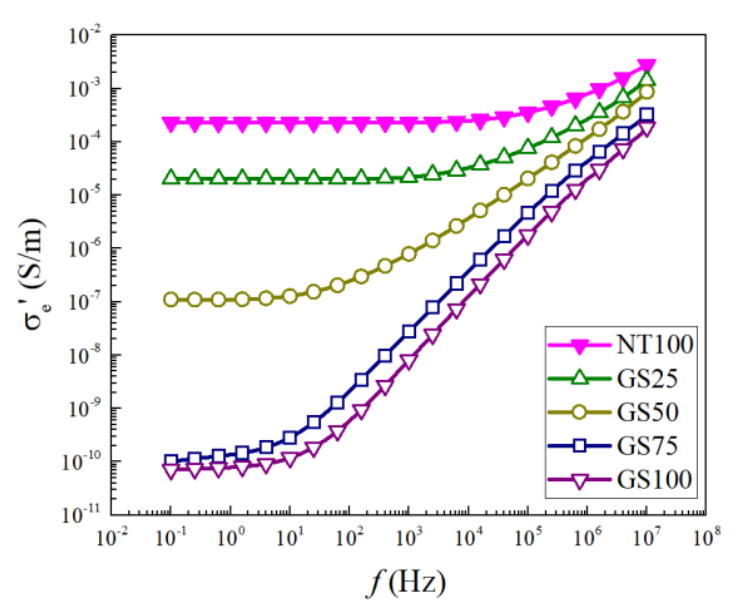

a)

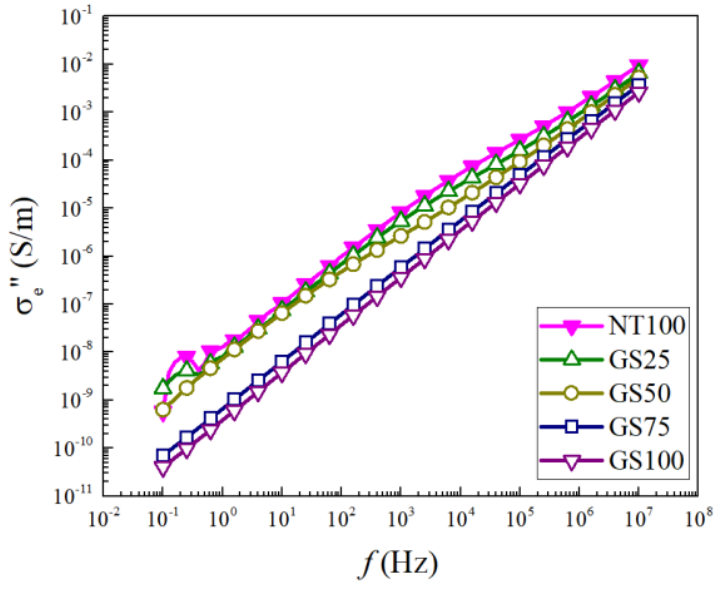

b) 


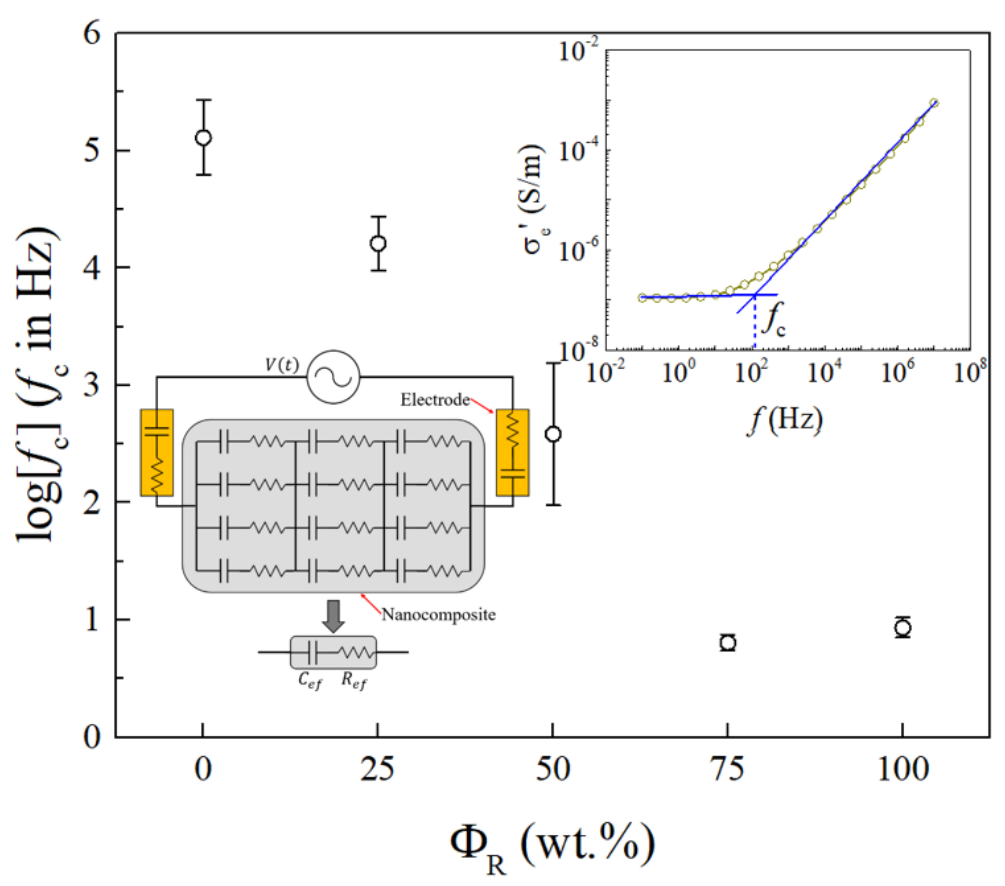

c)

Fig. 5. AC electrical response of the investigated materials. a) Real part of the electrical conductivity $\left(\sigma_{e}{ }^{\prime}\right)$, b) Imaginary part of the electrical conductivity $\left(\sigma_{e}{ }^{\prime \prime}\right)$, c) critical frequency $\left(f_{c}\right)$.

It is known that the electrical properties of nanocomposites with carbon nanostructures (MWCNTs or MLGSs) can be frequency-dependent [47,48]. The enormous difference in electrical conductivity between the carbon nanostructures and the polymer matrix can lead to a large charge accumulation at the filler/matrix interface above a certain frequency. This accumulated charge is proportional to the difference in conductivities, shifting the electrical response at a given frequency. This mechanism is described as a Maxwell-Wagner-Sillars (MWS) interfacial polarization, and accordingly, Xia et al. have proposed that the graphene/polymer interface can behave as a nanocapacitor [48]. The inset in Fig. 5c shows a schematic representation of the model proposed by Xia et al. [48], where the nanocomposite effective resistance $\left(R_{e f}\right)$ and capacitance $\left(C_{e f}\right)$ comes from a series-parallel combination of distributed resistance-capacitance elements. It is expected that the MWS effect becomes more important as $f$ increases. Increased frequency provide more energy to the charge carriers 
to hop through the nanostructure/polymer interface, rendering higher conductivity [48]. The switch between the resistive-like behavior to the capacitive one will occur when the interface of these nanocapacitors slows down (or blocks) the charge motion across it. The actual frequency where this occurs $\left(f_{c}\right)$, will depend on the type of nanostructure/polymer interfaces, filler concentration, dispersion state, particle morphology and mismatch in conductivities. In this case, there are one or two electro-conductive nanostructures within the insulating TF polymer, each one with different state of dispersion and morphology (see Fig. 2). Therefore, it is expected that different interfaces are formed between each of the nanocomposites examined, which explains the different contribution of the interfacial polarization to $\sigma_{e}{ }^{\prime}$, and the shift of $f_{c}$ as a function of $\Phi_{R}$ observed in Fig. 5c. Given the higher surface area of MLGSs compared to that of MWCNTs (see Table S1 of the supplementary information), MLGSs further promote the conditions for the MWS effect to occur. This may explain the decrease in $f_{c}$ with increased MLGS content observed in Fig. 5c.

\subsection{Mechanical and piezoresistivity properties of the nanocomposite tubes}

Figure 6 summarizes the mechanical response of nanocomposite tubes under internal pressure. The pressure $(P)$ - circumferential strain $\left(\varepsilon_{\theta}\right)$ response in Fig. 6a is rather linear below $\sim 150 \mathrm{kPa}$. Above this pressure, the curve acquires a nonlinear response until tube bursting at a pressure $P_{\text {Max }}$, which is summarized in Fig. 6b. The average burst pressure $\left(P_{\text {Max }}\right)$ increases with the inclusion of any of the nanostructures with respect to that of the TF tubes $\left(P_{\text {Max }}=222 \mathrm{kPa}\right)$, being higher $(311 \mathrm{kPa})$ for composites with only MWCNTs (NT100). For hybrid nanocomposites, the burst pressure decreases as the concentration of MLGSs increases. As for the elastic response, it is seen in Fig. 6c that the average compliance $(C)$ of the TF $\left(9.88 \times 10^{-4} \mathrm{kPa}^{-1} \approx 1.32 \times 10^{-2} \% / \mathrm{mmHg}\right)$ decreases with the inclusion of any 
carbon nanostructure, also achieving the stiffest composite for NT100 $\left(C=4.77 \times 10^{-4} \mathrm{kPa}^{-1}\right.$ $\left.\approx 0.64 \times 10^{-2} \% / \mathrm{mmHg}\right)$

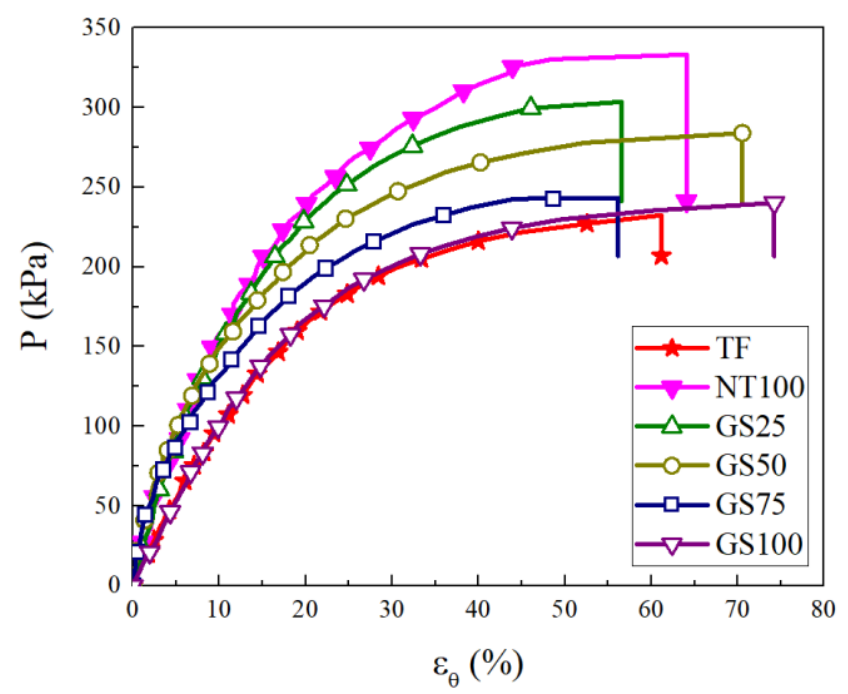

a)

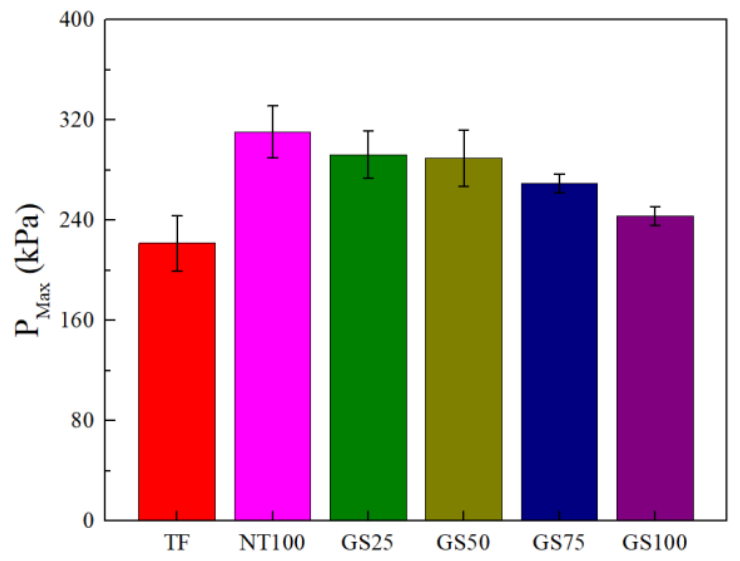

b)

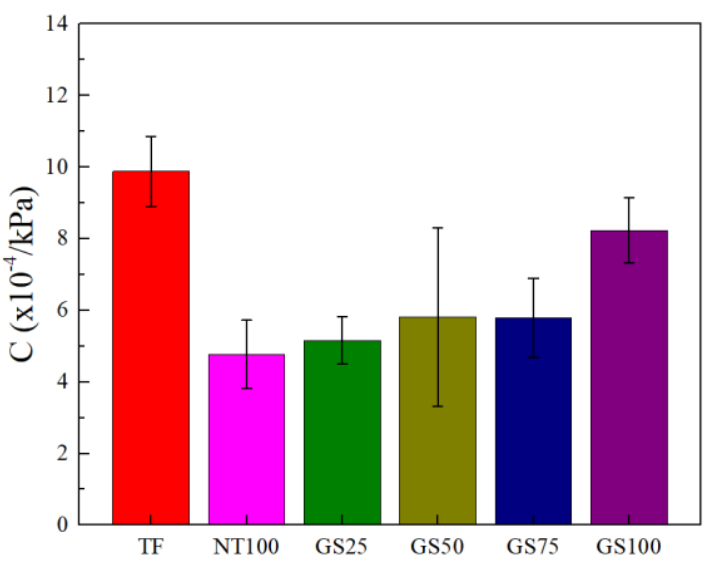

c)

Fig. 6. Mechanical properties of the nanocomposite tubes. a) Pressure-circumferential strain response, b) burst pressure $\left.\left(P_{\text {Max }}\right), \mathrm{c}\right)$ compliance $(C)$.

The DIC strain fields $\left(\varepsilon_{x}, \varepsilon_{y}, \varepsilon_{z}\right)$ of a representative (GS75) tube under internal pressure, at pressures of $75 \mathrm{kPa}$ and $150 \mathrm{kPa}$ are shown in Fig. 7. Since distinctive features where not observed for other nanocomposite tubes, strain fields of other selected nanocomposite tubes and the neat polymer are shown in Fig. S9 of section S6 in the supplementary information. Also, a video showing the DIC strain fields and failure of a tube is included in the supplementary information. Theory of elasticity indicates that the longitudinal strain $\left(\varepsilon_{x}\right)$ of 
a linear-elastic hollow cylinder with restricted ends (as in this case) subjected to internal pressure is uniform [49], which is consistent with what is observed in the DIC images for $\varepsilon_{x}$. In addition, this was further confirmed with a finite element analysis (FEA) describe in section S6 of the supplementary information. However, localized strain gradients up to $3 \%$ are observed, which are attributed to stress/strain concentrations and the elastomeric nature of the TF [50]. This becomes more evident as the pressure increases, since the elastomeric tubes are prone to bend laterally at higher pressures (which is not considered in the theory of elasticity). In the case of $\varepsilon_{y}$, theory of elasticity [49] and FEA (Fig. S10 of the supplementary information) indicates that $\varepsilon_{y}$ is maximum at the zenith $(y=0, z= \pm r$, where $r$ is the tube radius, see Fig. 1), decreasing symmetrically as $z$ approaches the azimuth or horizontal plane $(y=r, z=0)$. For $\varepsilon_{z}$, theory of elasticity and FEA (Fig. S10) predicts the maximum at the azimuth $(y=r, z=0)$, while for the zenith $(y=0, z= \pm r)$ the strain is minimum. The combination of these three strain fields (transformed to hoop and radial) under internal tube pressure cause the pressure-strain response observed in Fig. 6a. Overall, the strain fields predicted by theory of elasticity and by FEA (see Fig. S10) are in reasonable agreement with those measured by DIC in Fig. 7, but the measurements show localized strain gradients. This is because TF is not a linear elastic material, but rather an hyperelastic one, with large nonlinear deformation capabilities $[13,50]$. The gradients in the strain fields can also be influenced by the state of dispersion and distribution of the nanostructures within the nanocomposites (see Fig. 2 and 3). Imperfect adhesion between the tube layers may also be a contributing factor. 


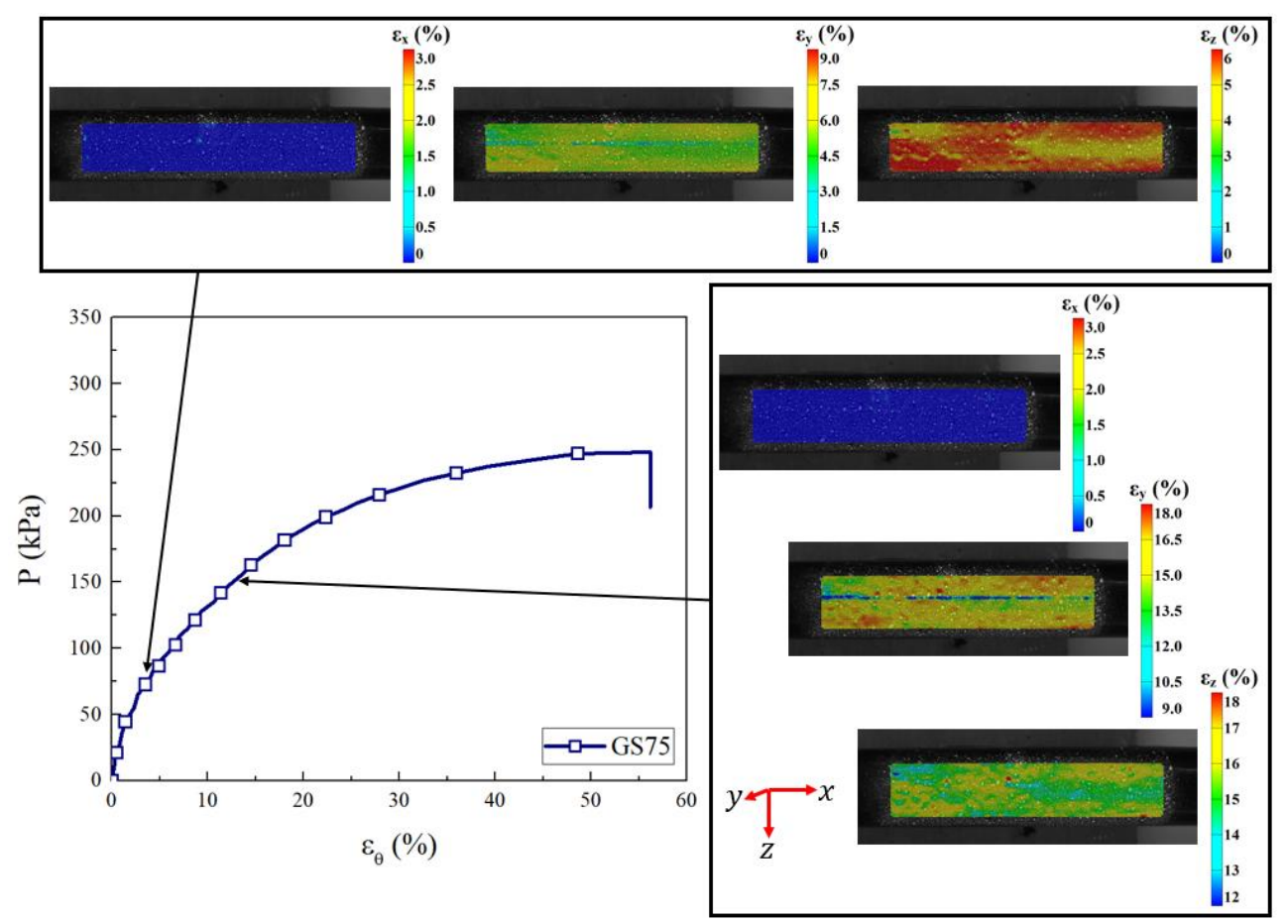

Fig. 7. DIC strain fields of a representative GS75 nanocomposite tube.

Figure 8 shows the piezoresistive response of the NT100 and GS25 tubes subjected to internal pressure. The rest of the tubes (GS50, GS75 and GS100) were not characterized because of their high resistivity. The curves of fractional change of electrical resistance $\left(\Delta R / R_{0}\right)$ are presented as a function of the circumferential strain $\left(\varepsilon_{\theta}\right)$ in Fig. 8a, and as a function of the internal pressure $(P)$ in Fig. 8b. From Fig. 8a it is observed that both nanocomposites have a nonlinear behavior with $\varepsilon_{\theta}$, and that GS25 has higher change in electrical resistance upon deformation. This change in electrical resistance becomes up to 1000 times for circumferential strains of $\sim 25 \%$, which renders a very high piezoresistive sensitivity (Fig. $8 \mathrm{c}$ and 7d). The sensitivity of both tubes to pressure is relatively low at pressures below 150 $\mathrm{kPa}$, with values of $\Delta R / R_{0} \sim 30(\mathrm{GS} 25)$ and $\sim 10(\mathrm{NT} 100)$ for $P=150 \mathrm{kPa}$. For $P>200 \mathrm{kPa}$, the values of $\Delta R / R_{0}$ for both composites are greatly increased, with a steep change of slope. Therefore, gage factors (Fig. 8c and $7 \mathrm{~d}, G F^{T}$ ) and pressure sensitivity factors (Fig. 8e and 8f, $P F$ ) were calculated in two regions (as described in section 2.5), and both factors were always 
significantly higher in the zone of higher pressures (region II). In the zone of lower pressures $\left(<35 \mathrm{kPa}\right.$, Fig. 8c), NT100 has an average gage factor of $G F^{T}{ }_{I}=71.0$, while GS25 presents $G F_{I}^{T}=89.1$. For the second zone (from $150 \mathrm{kPa}$ to $200 \mathrm{kPa}$, Fig. $8 \mathrm{~d}$ ), $G F_{I I}^{T}=2514$ and $G F_{I I}^{T}=4573$ for NT100 and GS25, respectively. Similarly, for the pressure factors, $P F_{I}=$ $4.84 \times 10^{-3} \mathrm{kPa}^{-1}$ for NT100, while $P F_{I}=11.6 \times 10^{-3} \mathrm{kPa}^{-1}$ for GS25. For higher pressures $(150-$ $200 \mathrm{kPa}), P F_{I I}=0.84 \mathrm{kPa}^{-1}$ for NT 100 and $P F_{I I}=4.59 \mathrm{kPa}^{-1}$ for GS25. Given the cylindrical geometry of the tubes and the internal pressure in the burst test, the tube strain in the principal axes are a combination of radial, circumferential (hoop), and axial (longitudinal) strain, forming a three-dimensional state of stress [49]. Notice that GS25 also showed collaborative effects in Fig. 4. Thus, the hybrid network formation favors the electromechanical sensitivity of the GS25 hybrid nanocomposite in a hyperelastic tube subjected to a complex threedimensional state of stress/strain, triggered by internal pressure.

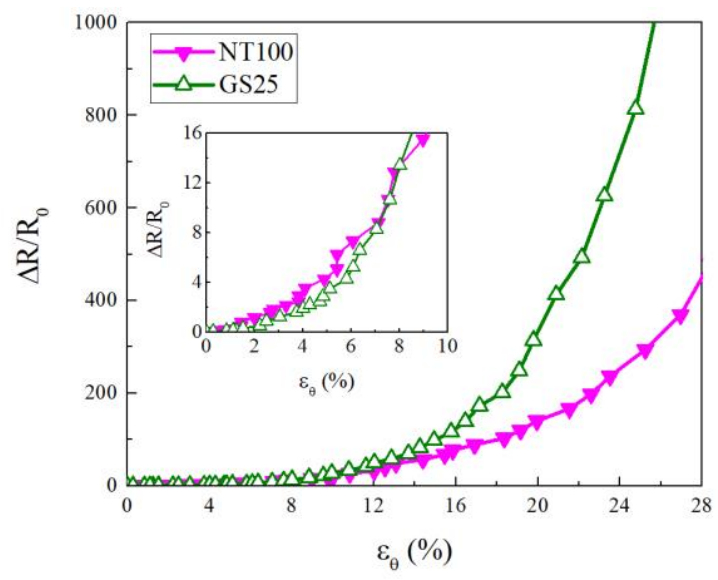

a)

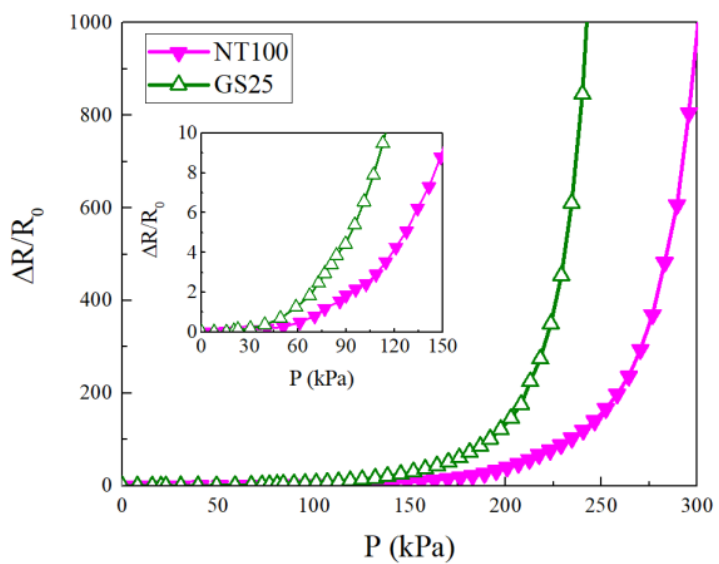

b) 


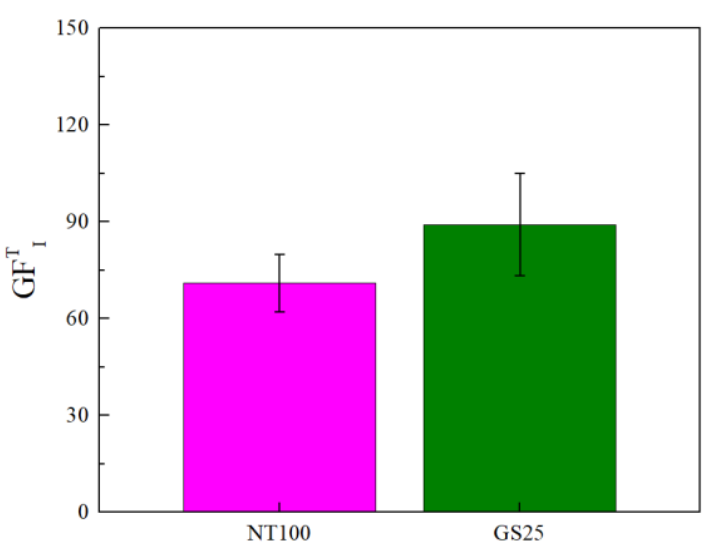

c)

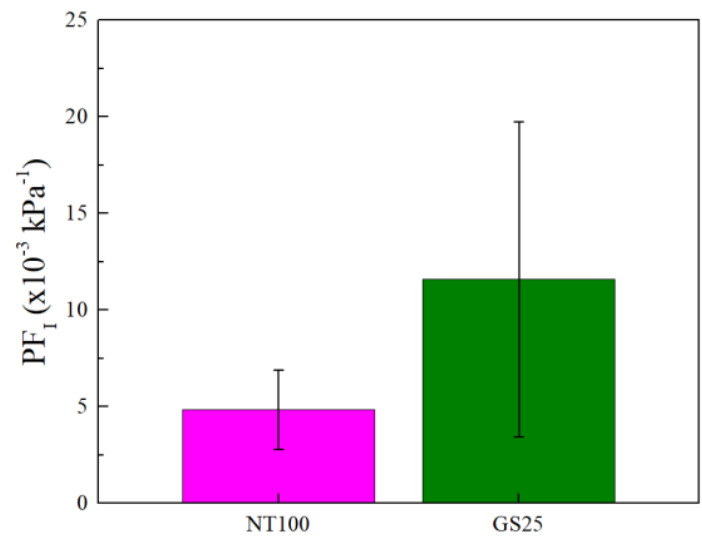

e)

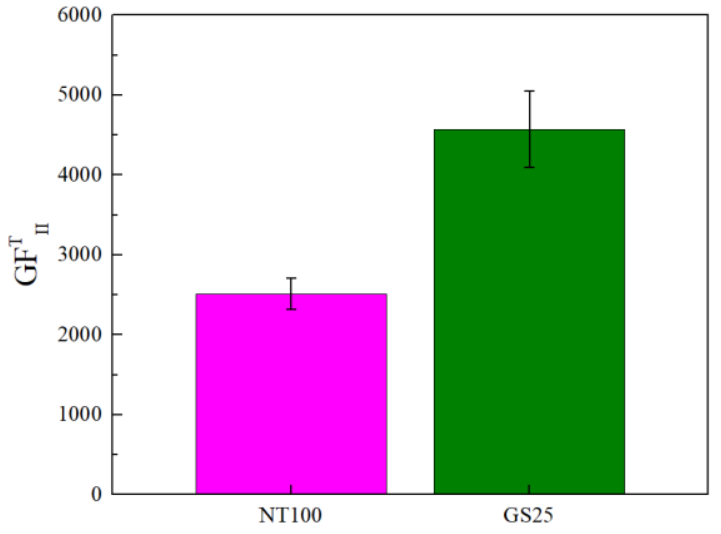

d)

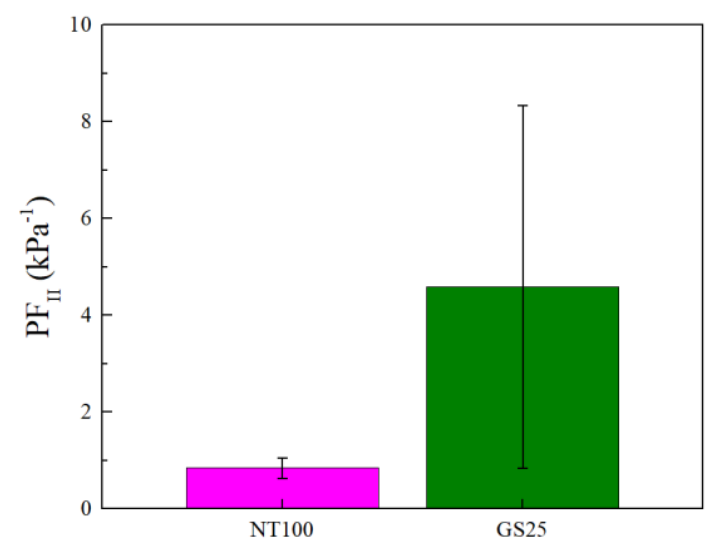

f)

Fig. 8. Piezoresistive properties of the nanocomposite tubes NT100 and GS25.

a) Piezoresistive response as a function of strain, b) Piezoresistive response as a function of pressure, c) gage factor in the interval $0 \leq \varepsilon_{\theta} \leq 5 \%\left(G F_{I}^{T}\right)$,d) gage factor in the interval

$\left.15 \% \leq \varepsilon_{\theta} \leq 20 \%\left(G F_{I I}^{T}\right), \mathrm{e}\right)$ pressure factor in the interval $0 \leq P \leq 35 \mathrm{kPa}\left(P F_{I}\right)$,

f) pressure factor in the interval $150 \mathrm{kPa} \leq P \leq 200 \mathrm{kPa}\left(P F_{I I}\right)$.

As context for the prospective applications of these tubes, the commercial medical pressure sensor NPC-100 from NovaSensor (Fremont, USA) [51] has a pressure sensitivity (pressure factor) of $3.75 \times 10^{-5} \mathrm{kPa}^{-1}$ [7], which is less than that of the tubes made with the nanocomposite GS25 herein $\left(11.6 \times 10^{-3} \mathrm{kPa}^{-1}\right)$. The cyclic response of such nanocomposite tubes would also be of great interest for developing commercial applications, since thermoplastic polyurethanes may present hysteresis in their mechanical and piezoresistive responses. The magnitude of such hysteresis depends on the rigid/flexible segment content, strain level, filler type, and concentration [52]. 


\section{Conclusions}

The electrical and piezoresistive behavior of a segmented aliphatic polyurethane (Tecoflex, TF) modified with multilayer graphene sheets (MLGSs), multiwall carbon nanotubes (MWCNTs), and a hybrid combination of both were investigated, using coupons in geometry of planar films and tubes. The logarithm of the DC electrical conductivity of the nanocomposite films presented a sigmoidal (Boltzmann) function with the relative concentration of MLGSs $\left(\Phi_{R}\right)$, with highest conductivity for the composites with only MWCNTs and the lowest one for those with only MLGSs. It was found that the measured DC conductivities of the hybrid films are contained within an area bounded by the predictions of the series and parallel semi-empirical models proposed herein, which are calibrated with measured data for composites with only MLGSs and MWCNTs. Hybrid nanocomposite films with 25 wt.\% of MLGSs and 75 wt.\% of MWCNTS $\left(\Phi_{R}=25\right.$ wt.\%, GS25) showed collaborative interactions, with an electrical conductivity higher than that of composites with the same amount of MWCNTs or MLGSs. Correlations with microscopic observations suggest that the elongated one-dimensional morphology and lower excluded volume of the MWCNTs with respect to MLGSs yields a more dispersed network for MWCNT composites. However, in this material system, the inclusion of small amounts of MLGSs can create interconnected agglomerates, which favor electrical conductivity. Dielectric spectroscopy showed a dependence of the AC electrical conductivity with frequency, which evidences a capacitive response at high frequencies; the onset frequency where capacitive effects significantly influence the impedance of the hybrid composites depends on the relative concentration of MLGSs, and occurs at lower frequencies as the relative concentration of MLGSs increases. Thus, the presence of MLGSs favors capacitive effects, which was 
explained by the Maxwell-Wagner-Sillars interfacial polarization mechanism and the larger surface area of the MLGSs over that of the MWCNTs.

The mechanical response of nanocomposite tubes subjected to internal pressure showed that the burst pressure and tube compliance also depend on the relative concentration of MLGSs. Tubes made of any of the nanocomposite films were much stiffer than those made of neat TF, by factors between 1.2 and 2.1 times. Composite tubes containing only MWCNTs showed the highest reinforcement effect (burst pressure and stiffness), once again due to the higher aspect ratio and one-dimensional character of the nanotubes. Full field strain fields of the pressurized tubes measured by digital image correlation indicated that the strain fields predicted by elasticity theory (and finite element analysis) are disturbed by localized strain gradients in this kind of elastomeric materials. The piezoresistive response of the nanocomposite tubes was nonlinear with a high piezoresistive sensitivity, especially for pressures greater than $60 \mathrm{kPa}$. The hybrid nanocomposites with $\Phi_{R}=25$ wt.\% (GS25) presented the highest sensitivity (pressure factor), being this $4.59 \mathrm{kPa}^{-1}$ in the range of 150 to $200 \mathrm{kPa}$. The results indicate that elastomeric tubes fabricated with these nanocomposites could be used as smart materials in vast applications such as medicine, flexible robotics, and aerospace (astronaut) suits.

\section{Acknowledgments}

This work was partially supported by ONRG grant N62909-19-1-2119 to Dr. FA. Additional support from CONACYT grants No. 2262, 1360 and infrastructure grant No. 268595 (CICY) is also acknowledged. Physico-chemical characterizations performed by Dr. Alejandro May and M.C. Carlos Sierra, as well as transmission electron microscopy images obtained by Dr. Ignacio González under the supervision of Dr. Mark Rümmeli (IFW-Leibniz) are strongly appreciated. CPA also wishes to thank Estefanía López and Carlos Falla (CINVESTAV) for 
their assistance in the 4-wire electrical measurements, Perla Aranda for aesthetic edition of microscopy images, and Céline Combettes (LAPLACE) for her technical assistance.

\section{References}

[1] Spillman Jr WB, Sirkis JS, Gardiner PT. Smart materials and structures: What are they? Smart Mater Struct 1996;5:247-254. doi:10.1088/0964-1726/5/3/002.

[2] Ferreira ADBL, Nóvoa PRO, Marques AT. Multifunctional material systems: A stateof-the-art review. Compos Struct 2016;151:3-35. doi:10.1016/j.compstruct.2016.01.028.

[3] Kang I, Heung YY, Kim JH, Lee JW, Gollapudi R, Subramaniam S, et al. Introduction to carbon nanotube and nanofiber smart materials. Compos Part B Eng 2006;37:38294. doi:10.1016/j.compositesb.2006.02.011.

[4] Ilievski F, Mazzeo AD, Shepherd RF, Chen X, Whitesides GM. Soft robotics for chemists. Angew Chemie - Int Ed 2011;50:1890-5. doi:10.1002/anie.201006464.

[5] Cianchetti M, Laschi C, Menciassi A, Dario P. Biomedical applications of soft robotics. Nat Rev Mater 2018;3:143-53. doi:10.1038/s41578-018-0022-y.

[6] Anderson IA, Gisby TA, McKay TG, O’Brien BM, Calius EP. Multi-functional dielectric elastomer artificial muscles for soft and smart machines. J Appl Phys 2012;112:041101. doi:10.1063/1.4740023.

[7] Yao J, Yang X, Shao N, Luo H, Zhang T, Jiang W. A flexible and highly sensitive piezoresistive pressure sensor based on micropatterned films coated with carbon nanotubes. J Nanomater 2016;2016:1-5.

[8] Loew P, Brill M, Rizzello G, Seelecke S. Development of a nonintrusive pressure sensor for polymer tubes based on dielectric elastomer membranes. Sensors Actuators, A Phys 2019;292:1-10. doi:10.1016/j.sna.2019.03.006.

[9] Zhao Y, Huang Y, Hu W, Guo X, Wang Y, Liu P, et al. Highly sensitive flexible strain sensor based on threadlike spandex substrate coating with conductive nanocomposites for wearable electronic skin. Smart Mater Struct 2019;28:035004. doi:10.1088/1361- 
665X/aaf3ce.

[10] Guo X, Huang Y, Zhao Y, Mao L, Gao L, Pan W, et al. Highly stretchable strain sensor based on SWCNTs/CB synergistic conductive network for wearable human-activity monitoring and recognition. Smart Mater Struct 2017;26:095017. doi:10.1088/1361$665 X / a a 79 c 3$.

[11] Veeralingam S, Priya S, Badhulika S. NiO nanofibers interspersed sponge based low cost, multifunctional platform for broadband UV protection, ultrasensitive strain and robust finger-tip skin inspired pressure sensor. Chem Eng J 2020;389: 124415. doi:10.1016/j.cej.2020.124415.

[12] Chen Y, Yu M, Bruck HA, Smela E. Compliant multi-layer tactile sensing for enhanced identification of human touch. Smart Mater Struct 2018;27:125009. doi:10.1088/1361$665 X / a a e a e 4$.

[13] Bautista-Quijano JR, Avilés F, Cauich-Rodriguez J V., Schönfelder R, Bachmatiuk A, Gemming $\mathrm{T}$, et al. Tensile piezoresistivity and disruption of percolation in singlewall and multiwall carbon nanotube/polyurethane composites. Synth Met 2013;185186:96-102. doi:10.1016/j.synthmet.2013.09.041.

[14] Boland CS, Khan U, Backes C, O’Neill A, McCauley J, Duane S, et al. Sensitive, highstrain, high-rate bodily motion sensors based on graphene-rubber composites. ACS Nano 2014;8:8819-30. doi:10.1021/nn503454h.

[15] Niu D, Jiang W, Ye G, Wang K, Yin L, Shi Y, et al. Graphene-elastomer nanocomposites based flexible piezoresistive sensors for strain and pressure detection. Mater Res Bull 2018;102:92-9. doi:10.1016/j.materresbull.2018.02.005.

[16] Wang X, Meng S, Tebyetekerwa M, Li Y, Pionteck J, Sun B, et al. Highly sensitive and stretchable piezoresistive strain sensor based on conductive poly(styrenebutadiene-styrene)/few layer graphene composite fiber. Compos Part A Appl Sci Manuf 2018;105:291-9. doi:10.1016/j.compositesa.2017.11.027.

[17] Papageorgiou DG, Kinloch IA, Young RJ. Graphene/elastomer nanocomposites. Carbon 2015;95:460-84. doi:10.1016/j.carbon.2015.08.055. 
[18] Sadasivuni KK, Ponnamma D, Thomas S, Grohens Y. Evolution from graphite to graphene elastomer composites. Prog Polym Sci 2014;39:749-80. doi:10.1016/j.progpolymsci.2013.08.003.

[19] Zheng Y, Li Y, Dai K, Liu M, Zhou K, Zheng G, et al. Conductive thermoplastic polyurethane composites with tunable piezoresistivity by modulating the filler dimensionality for flexible strain sensors. Compos Part A Appl Sci Manuf 2017;101:41-9. doi:10.1016/j.compositesa.2017.06.003.

[20] Hernández M, Bernal MM, Grande AM, Zhong N, van der Zwaag S, García SJ. Effect of graphene content on the restoration of mechanical, electrical and thermal functionalities of a self-healing natural rubber. Smart Mater Struct 2017;26:085010. doi.org/10.1088/1361-665X/aa71f5.

[21] Paszkiewicz S, Szymczyk A, Sui XM, Wagner HD, Linares A, Ezquerra TA, et al. Synergetic effect of single-walled carbon nanotubes (SWCNT) and graphene nanoplatelets (GNP) in electrically conductive PTT-block-PTMO hybrid nanocomposites prepared by in situ polymerization. Compos Sci Technol 2015;118:72-7. doi:10.1016/j.compscitech.2015.08.011.

[22] Das A, Kasaliwal GR, Jurk R, Boldt R, Fischer D, Stöckelhuber KW, et al. Rubber composites based on graphene nanoplatelets, expanded graphite, carbon nanotubes and their combination: A comparative study. Compos Sci Technol 2012;72:1961-7. doi:10.1016/j.compscitech.2012.09.005.

[23] Hwang SH, Park HW, Park Y Bin, Um MK, Byun JH, Kwon S. Electromechanical strain sensing using polycarbonate-impregnated carbon nanotube-graphene nanoplatelet hybrid composite sheets. Compos Sci Technol 2013;89:1-9. doi:10.1016/j.compscitech.2013.09.005.

[24] Safdari M, Al-Haik MS. Synergistic electrical and thermal transport properties of hybrid polymeric nanocomposites based on carbon nanotubes and graphite nanoplatelets. Carbon 2013;64:111-21. doi:10.1016/j.carbon.2013.07.042.

[25] Aguilar-Bolados H, Lopez-Manchado MA, Brasero J, Avilés F, Yazdani-Pedram M. 
Effect of the morphology of thermally reduced graphite oxide on the mechanical and electrical properties of natural rubber nanocomposites. Compos Part B Eng 2016;87:350-6. doi:10.1016/j.compositesb.2015.08.079.

[26] Szeluga U, Kumanek B, Trzebicka B. Synergy in hybrid polymer/nanocarbon composites. A review. Compos Part A Appl Sci Manuf 2015;73:204-31. doi:10.1016/j.compositesa.2015.02.021.

[27] Kong KTS, Mariatti M, Rashid AA, Busfield JJC. Enhanced conductivity behavior of polydimethylsiloxane (PDMS) hybrid composites containing exfoliated graphite nanoplatelets and carbon nanotubes. Compos Part B Eng 2014;58:457-62. doi:10.1016/j.compositesb.2013.10.039.

[28] Nakamura A, Hamanishi T, Kawakami S, Takeda M. A piezo-resistive graphene strain sensor with a hollow cylindrical geometry. Mater Sci Eng B 2017;219:20-7. doi:10.1016/j.mseb.2017.02.012.

[29] Bautista-Quijano JR, Pötschke P, Brünig H, Heinrich G. Strain sensing, electrical and mechanical properties of polycarbonate/multiwall carbon nanotube monofilament fibers fabricated by melt spinning. Polymer 2016;82:181-9. doi:10.1016/j.polymer.2015.11.030.

[30] Avilés F, May-Pat A, Canché-Escamilla G, Rodríguez-Uicab O, Ku-Herrera JJ, Duarte-Aranda S, et al. Influence of carbon nanotube on the piezoresistive behavior of multiwall carbon nanotube/polymer composites. J Intell Mater Syst Struct 2016;27:92103. doi:10.1177/1045389X14560367.

[31] Pal R. Electromagnetic, mechanical, and transport properties of composite materials. vol. 158. Boca Raton: CRC Press - Taylor \& Francis Group; 2015.

[32] ANSI/AAMI/ISO 7198:1998/2001/(R)2004 “Cardiovascular implants - Tubular vascular prostheses". Association for the Advancement of Medical Instrumentation; 2001.

[33] Pérez-Aranda C, Gamboa F, Castillo-Cruz O, Cauich-Rodríguez J V., Avilés F. Design and analysis of a burst strength device for testing vascular grafts. Rev Sci Instrum 
2019;90:014301. doi:10.1063/1.5037578.

[34] Li J, Ma PC, Chow WS, To CK, Tang BZ, Kim JK. Correlations between percolation threshold, dispersion state, and aspect ratio of carbon nanotubes. Adv Funct Mater 2007;17:3207-15. doi:10.1002/adfm.200700065.

[35] Liu M, Papageorgiou DG, Li S, Lin K, Kinloch IA, Young RJ. Micromechanics of reinforcement of a graphene-based thermoplastic elastomer nanocomposite. Compos Part A Appl Sci Manuf 2018;110:84-92. doi:10.1016/j.compositesa.2018.04.014.

[36] Liu M, Kinloch IA, Young RJ, Papageorgiou DG. Modelling mechanical percolation in graphene-reinforced elastomer nanocomposites. Compos Part B Eng 2019;178:107506. doi:10.1016/j.compositesb.2019.107506.

[37] Konios D, Stylianakis MM, Stratakis E, Kymakis E. Dispersion behaviour of graphene oxide and reduced graphene oxide. J Colloid Interface Sci 2014;430:108-12. doi:10.1016/j.jcis.2014.05.033.

[38] Al-saleh MH. Electrical and mechanical properties of graphene/carbon nanotube hybrid nanocomposites. Synth Met 2015;209:41-6. doi:10.1016/j.synthmet.2015.06.023.

[39] Balberg I, Anderson CH, Alexander S, Wagner N. Excluded volume and its relation to the onset of percolation. Phys Rev B Condens Matter Mater Phys 1984;30:3933-43. doi:10.1103/PhysRevB.30.3933.

[40] Ren X, Chaurasia AK, Oliva-Avilés AI, Ku-Herrera JJ, Seidel GD, Avilés F. Modeling of mesoscale dispersion effect on the piezoresistivity of carbon nanotube-polymer nanocomposites via 3D computational multiscale micromechanics methods. Smart Mater Struct 2015;24:065031. doi.org/10.1088/0964-1726/24/6/065031.

[41] Li C, Thostenson ET, Chou T-W. Dominant role of tunneling resistance in the electrical conductivity of carbon nanotube-based composites. Appl Phys Lett 2007;91:16-8. doi:10.1063/1.2819690.

[42] Mohiuddin M, Hoa S V. Estimation of contact resistance and its effect on electrical conductivity of CNT/PEEK composites. Compos Sci Technol 2013;79:42-8. 
doi:10.1016/j.compscitech.2013.02.004.

[43] Aguilar JO, Bautista-Quijano JR, Avilés F. Influence of carbon nanotube clustering on the electrical conductivity of polymer composite films. Express Polym Lett 2010;4:292-9. doi:10.3144/expresspolymlett.2010.37.

[44] Can-Ortiz A, Abot JL, Avilés F. Electrical characterization of carbon-based fibers and their application for sensing relaxation-induced piezoresistivity in polymer composites. Carbon 2019;145:119-30. doi:10.1016/j.carbon.2018.12.108.

[45] Zhao YP, Wei BQ, Ajayan PM, Ramanath G, Lu T-M, Wang G-C, et al. Frequencydependent electrical transport in carbon nanotubes. Phys Rev B - Condens Matter Mater Phys 2001;64:1-4. doi:10.1103/PhysRevB.64.201402.

[46] Ke K, McMaster M, Christopherson W, Singer KD, Manas-Zloczower I. Effects of branched carbon nanotubes and graphene nanoplatelets on dielectric properties of thermoplastic polyurethane at different temperatures. Compos Part B Eng 2019;166:673-80. doi:10.1016/j.compositesb.2019.03.005.

[47] Zhao H, Bai J. Highly sensitive piezo-resistive graphite nanoplatelet-carbon nanotube hybrids/polydimethylsilicone composites with improved conductive network construction. ACS Appl Mater Interfaces 2015;7:9652-9. doi:10.1021/acsami.5b01413.

[48] Zhao H, Yang M, He D, Liu Y, Bai J, Wang H, et al. Typical synergistic effect of graphite nanoplatelets and carbon nanotubes and its influence on polymer-based dielectric composites. High Volt 2016;1:140-5. doi:10.1049/hve.2016.0058.

[49] Xia X, Zhong Z, Weng GJ. Maxwell-Wagner-Sillars mechanism in the frequency dependence of electrical conductivity and dielectric permittivity of graphene-polymer nanocomposites. Mech Mater 2017;109:42-50. doi:10.1016/j.mechmat.2017.03.014.

[50] Tiimoshenko S, Goodier JN. Theory of elasticity. 1st ed. New York: McGraw-Hill; 1951.

[51] Qi HJ, Boyce MC. Stress-strain behavior of thermoplastic polyurethanes. Mech Mater 2005;37:817-39. doi:10.1016/j.mechmat.2004.08.001. 
2

3

4

5

6

7

8

9

10

11

12

13

14

15

16

17

18

19

20

21

22

23

24

25

26

27

28

29

30

31

32

33

34

35

36

37

38

39

40

41

42

43

44

45

46

47

48

49

50

51

52

53

54

55

56

57

58

59

60

[52] Amphenol Advanced Sensors, St. Marys, PA, USA. https://www.amphenolsensors.com/. March 2020.

[53] Lozano-Pérez C, Cauich-Rodríguez JV, Avilés F. Influence of rigid segment and carbon nanotube concentration on the cyclic piezoresistive and hysteretic behavior of multiwall carbon nanotube/segmented polyurethane composites. Compos Sci Technol 2016;128: 25-32. doi:10.1016/j.compscitech.2016.03.010. 